\title{
A propósito do Outro, etnográfico e em psicanálise
}

\author{
About the Other, ethnographic and in psychoanalysis
}

\section{José Francisco Miguel Henriques Bairrão}

Psicólogo, Doutor em Filosofia pela Universidade Estadual de Campinas (Unicamp), docente do Departamento de Psicologia e Educação da Faculdade de Filosofia Ciências e Letras de Ribeirão Preto (FFCLRP) da Universidade de São Paulo (USP), Ribeirão Preto, SP - Brasil, e-mail: bairrao@usp.br

\section{Resumo}

Oriunda da filosofia, a categoria de alteridade contemporaneamente assumiu posição de destaque em disciplinas tais como a antropologia e a psicanálise. Mediante um prévio esclarecimento da sua elaboração no contexto da segunda - na qual a noção de Outro se apresenta indissociável de uma reflexão sobre a noção de sujeito e o estatuto do inconsciente -, vai argumentar-se a favor da aplicação da sua compreensão psicanalítica ao âmbito dos registros etnográficos. Ao implementá-la, conclui-se que uma boa etnografia depende da particularidade dos traços do observador subtraídos à sua observação. A psicanálise mostra-se imprescindível para consolidar uma metodologia à altura das disciplinas científicas cujo 'objeto' não seja uma coisa, mas sim alguém.

Palavras-chave: Lacan. Sujeito. Alteridade. Psicanálise. 


\section{Abstract}

Proceeding from Philosophy, the category of Otherness nowadays acquired prominence in disciplines such as Anthropology and Psychoanalysis. By means of a previous clarification of its psychoanalytic elaboration - in which Otherness can't be isolated from a reflection about the Self and the Unconscious -, it will be argued in favor of the application of its psychoanalytic understanding to ethnographic records. By implementing it, it was concluded that a good ethnography depends on particular traits of the observer, subtracted from his observation. Psychoanalysis proves to be essential to consolidate a methodology in scientific disciplines whose 'object' is not one thing, but someone.

Keywords: Lacan. Self. Otherness. Psychoanalysis.

Lacan propõe uma articulação muito peculiar da psicanálise à filosofia. Toda e qualquer pessoa, inclusive o filósofo, estaria antes do mais inconscientemente envolvida num razoar a respeito da sua própria condição de ser e apenas em alguns casos, muito talentosos, isso se manifestaria verbal e conscientemente em sistemas e teses filosóficas. É por isso que chega a dizer que não há necessidade de construir ou explicitar uma ontologia em psicanálise, porque, queira-se ou não, isso acontece inconscientemente (LACAN, 1981). Todos somos habitados por sofisticadas questões ontológicas, independentemente da habilidade profissional de as enunciar teórica e conscientemente (LACAN, 1966).

Não há razão para não alargar essa tese do divã ao social. Pelo contrário, o tipo de soluções encontradas em diferentes sociedades para lidar com essas questões pode ser indicativo de regularidades estruturais que permitam, se não encontrar uma solução para esse tipo de dúvida, constituinte do humano, elencar variados tipos de respostas.

Com base na tese da presença do mesmo tipo de problemática a respeito do sujeito em qualquer cultura, talvez se possa mapear o modo como se pode configurar e ser abordada a categoria de alteridade, menos numa perspectiva psicanalítica e em particular clínica, mas por meio do modo como se tenha apresentado em etnografias, tendo em 
vista não apenas que o 'nativo' encarna o Outro, como também e principalmente porque elas são obrigadas a lidar com a forma pela qual os 'nativos' ousam tratar o observador etnográfico como seu outro.

Por favorecer a admissão do Outro como terceiro estética e espacialmente constituído, a elaboração psicanalítica da alteridade pode ser pertinente para refletir todo e qualquer campo cuja circunstância instancie algum 'ele'. Está em jogo uma questão fundamental para uma epistemologia e teoria psicanalítica, e talvez mesmo para qualquer ciência humana propriamente dita: o sujeito, deslocado ou acolhido na forma do Outro. Circunscritora de um âmbito de inefabilidade avesso à psicologia e à ontologia, a abordagem psicanalítica da alteridade é útil, não apenas para evitar o descaminho da propositividade psicológica e da coisificação psicologista do sujeito, como também para prevenir o risco de conferir opacidade à enunciação do Outro.

Para ilustrar essa tese serão apresentados alguns tipos de dispositivos culturais que visam a dar forma e lidar com o Outro, tal como 'empiricamente' puderam ser etnografados em contextos africanos. Objetiva-se examinar até que ponto a construção da categoria em psicanálise - tal como efetivamente avançada de maneira original por Lacan, e sem a mínima intenção de subsumi-la ou correlacioná-la a constructos filosóficos supostamente equivalentes - pode ser útil para trazer inteligibilidade a processos que motivam o seu emprego etnográfico e a impasses que porventura possam embaralhar os etnólogos a seu respeito, quando ela é entendida apenas como fonte de distúrbios cognitivos e de erros de avaliação (o malfadado etnocentrismo) e não se reconhecer o Outro como eminentemente constituinte do ser próprio.

\section{Alteridade em psicanálise}

Em psicanálise, a alteridade é praticamente tudo, não fosse ela a mais promissora psicologia do futuro. No entanto, é possível resumir o de que se trata com base em quatro teses que resumem bem a sua abordagem pela psicanálise lacaniana: 
a) O Outro simbólico: o Outro 'comporta-se' intrinsecamente como linguagem. Não é uma abstração de interlocutores empíricos efetivos, posto que estes não deveriam ser interpretados como redutíveis à concretude que admita uma intersubjetividade, na medida em que originariamente o sujeito se inscreve como outro perante si mesmo e perante outrem. Desse modo a psicanálise também reitera a sua oposição a uma objetivação do sujeito.

b) O Outro vazio: a alteridade levanta a questão da consistência do Outro. Não há encontro possível entre sujeito e Outro, pelo menos absoluto. O Outro apresenta-se (como conjunto) vazio. Tratase de uma faceta concomitante e complementar da sua natureza simbólica. O Outro real apresenta-se ausente.

c) O Outro sexo: a alteridade remete ao sexual, psicanaliticamente concebido de maneira ampliada, como sentido além dos elementos discretos (significantes) que constituem a 'unidade de sentido' (un de sens). No limite o Outro é Outro sexo, 'indecente' (indecent). Qualquer composição significante, fruição de 'unida$\mathrm{de}^{\prime}$, testemunha e tem como pano de fundo a natureza sexual do sentido.

d) O Outro gozo: subjacente ao Outro sempre há uma questão a respeito da subsistência de si. O sujeito não goza do 'seu' ser, 'é' impossível.

Para melhor sublinhar que sujeito algum admite o tratamento de 'coisa' objetiva, por se tratar do contrário (remeter à agência em si mesma), Lacan reitera que "tudo que se deixa apreender na função do significante nunca mais pode ser dois [deles], ${ }^{1}$ sem que se abra no lugar do Outro aquilo a que [...] conferi o status de conjunto vazio" (LACAN, 2008, p. 364, grifo do autor). A alteridade é indissociável da sua mediação simbólica, e para muitos efeitos pode ser referida como a totalidade das suas possibilidades. O sentido depende da acontecência temporal de combinatórias significantes, no âmbito da qual, ao passar do um ao dois (deux) ou de um primeiro significante (de si) ao significante

Ao ler Lacan, ainda mais os seminários, é inadmissível desconsiderar as homofonias, porque elas nunca são irrelevantes. 
deles (d'eux), não se introduz positivamente uma soma, mas um e zero (LACAN, 2008).

Para estabelecer o seu argumento, Lacan desvia-se por considerações da teoria dos conjuntos, quando em verdade o que parece querer dizer e, aparentemente, 'provar' ou tornar mais plausível, é que o sujeito não pode reduzir-se à sua inscrição num conjunto de marcas que, relativamente a outras, signifiquem-no. Ou seja, que é impossível dizê-lo ou reduzi-lo ao significável, o que parece ser razoável, se está em pauta um irredutível agente, nunca objetivável. Algo escapa à alçada do Outro, o sujeito em si mesmo, por ser não significante ou remeter a um futuro anterior, ser simbolizado a posteriori e parcialmente.

Desse modo, qualquer saber estará sempre articulado a um sujeito incapturável, desejante, que emerge em significantes (o Outro), mas não se reduz a eles. O Outro é 'furado' e nesse furo encontra-se algo que remete ao próprio sujeito, que tem um estatuto precário, atravessado constitutivamente pelo que não é 'eu', outro. Um 'não eu' paradoxalmente constituinte de 'si'. Por isso Lacan dirá que "o Outro fornece apenas a textura do sujeito, ou seja, sua topologia" (LACAN, 2008, p. 64).

O Outro sempre pode ser substituído pela relação do sujeito com o Outro, ou seja, não há apreensão do Outro em si. E se subtrair-se ao Outro o sujeito, que é o que lá falta, encontra-se um furo que se consubstancia em topos da não relação com o Outro. A esse respeito esclarece que "o objeto $a$ é o furo que se designa no nível do Outro como tal, quando ele é questionado em sua relação com o sujeito" (LACAN, 2008, p. 59).

No fundo não se encontra alguém, há nada de Outro, o que o leva a negar a relação com o Outro além da mera repetição da falta de um Outro - problemática que aborda especialmente pelo viés da castração e da relação sexual, tendo em vista que 'a mulher' dá corpo ao Outro (mais precisamente, é um dos seus avatares psicanaliticamente mais significativos, por ser um dos que se propõem para além de qualquer sentido). Contra a (suposta) ingenuidade inerente às tentativas de positivar uma interlocução com gente concreta, embora diferente de 'nós', a rigor seria necessário partir não da ideia de Outro como alguém, mas de um outro entendido como 'redutível' a significante inscrito no Outro 
(LACAN, 2008). Como da perspectiva psicanalítica um outro não se compõe em dois, de modo algum o Outro é um. Um é mais do que o Outro. Nenhum significante sequer pode ser o representante de si mesmo a não ser distinguindo-se de si, ou seja, sendo outro separado da sua própria inscrição, Outro de si mesmo.

Essa irrealização do Outro, que torna precário o estatuto do próprio ser, está a serviço de uma noção de alteridade à altura de dar conta da ferida da relação do sujeito consigo mesmo. Nenhuma soma de um com outro pode totalizar-se numa cifra qualquer, de um dois adicionado, ou conduzir a uma sonhada união. Não se goza do ser: "à medida mesma da sua perfeição, fica inteiramente excluído o 'eu' do gozo" (LACAN, 2008, p. 132).

Quer como colapso subjetivo, quer como assentimento de sentido, o gozo tem um estatuto paradoxal, equivalente ao ser, mas um ser sem ser; ser como falta em ser (pano de fundo do desejo que é falta em ser), ou ser sem sujeito quando colapsa o desejo. Lacan reporta-se a uma especificidade que demarca o campo da psicanálise do da filosofia, ou pelo menos da ontologia, a qual marca a sua maior originalidade filosófica. Ser torna-se uma categoria psicanalítica, na medida em que se alastra de categoria metafísica, tateada mentalmente, a todo o âmbito da implicação do sujeito com o seu corpo e sua existência. Gozar é ouvir sentido, mas um sentido não restrito a qualquer significado de ser; um sentido que se alastra a todos os sentidos (sensações). É relativamente a isso que a questão do sujeito fica problemática, mais exatamente, a sua subsistência (BAIRRÃO, 2004).

Para o psicanalista, "a topologia do gozo é a topologia do sujeito" (LACAN, 2008, p. 112). O sujeito precisa do Outro para se produzir sentido, mas este sempre é incompleto ou insuficiente. Só há relação - ou melhor, ligação - entre significantes, o que 'acende' o sujeito (ser desejante, ser faltante) à custa da reprodução da falta.

Uma alteridade insubsistente é constituinte do ser sujeito, ao custo de ser sem ser (BAIRRÃO, 2004), e para tanto Lacan nada supõe de consubstancial ao Outro além da significância. Do lado do Outro é um traço do sujeito (um Outro) quem responde. Dessa forma, contra as aparências, almeja-se garantir a não redução de outrem a 'objeto' empírico, uma 
vez que o que se garante é que ele entra na 'nossa' economia psíquica na qualidade de um significante perante o qual 'nos' representamos:

esse significante perante o qual o sujeito se representa é, propriamente, esse um Outro. Vocês o veem inscrito aqui como um, na medida em que ele é o recurso perante o qual aquilo que tem que funcionar de sujeito se representa no campo do Outro (LACAN, 2008, p. 365).

Ao que acrescenta: "como tal, esse um no Outro não pode deixar de comportar o um-a-mais do conjunto vazio".

Ou seja, não apenas cada sujeito tem, a cada tempo, o 'seu' Outro, um Outro (o que é da máxima importância para que o diferente e o estrangeiro não sejam pensados como pura e simplesmente alheios e exteriores a um 'observador'), como também esse Outro tem de ser vazio, 'des-ser', sob pena de gozo. Se o Outro se perfizesse como Um, e não como 'um Outro', não haveria reiteração da falta e da castração, haveria um e um, e portanto dois, e portanto o pior, risco de encontro, tropeço, com o gozo. Afinal,

tudo o que produz nossa experiência só pode girar, revolver e retornar sempre ao foco da questão da subsistência do sujeito, que é o eixo, o axioma indispensável para nunca perdermos de vista aquilo com que temos de lidar no concreto [...] (LACAN, 2008, p. 349).

Mas o mais fundamental para o presente propósito é reter que qualquer significante perante o qual um sujeito se represente, estrutura mínima constituinte da sua precariedade em ser, reitera replicação, não de si, mas de um Outro. Desse modo, embora 'estranho', algum Outro nunca lhe é alheio. É consubstancial ao sujeito, faz-lhe falta para ser 'alguém'; ou seja, não há propriamente sujeito sem alteridade.

Em síntese, para a psicanálise a alteridade é intrinsecamente negatividade constituinte do sujeito (é menos 'eu'). O lugar de si é outro e, em vez de ser, o estatuto do sujeito é paradoxal e de uma intrínseca precaridedade. Ser e sujeito não se conjugam, porque o Outro continua, à sua maneira, outro, embora incorporado como núcleo vazio do si mesmo. O Outro é menos que um. É subtraído de ser um. 
É tendo em vista essa formulação que, sem a pretensão de esgotar o assunto, se passa a examinar algumas formas pelas quais a temática da alteridade tem sido apresentada pelo lado do ofício etnográfico.

\section{Alteridade etnográfica}

A retórica lacaniana em principio soa distante da alteridade em etnografia. Nesta o Outro não se discute nos termos de uma suposta vacuidade do ser. Surge quase como um dado positivo, um fato cultural entendido de modo bastante diverso das lacanianas considerações sobre o estatuto do fato 'observado' como dependente de uma enunciação do Outro.

A questão que se põe é que, se o Outro for abordado como diferença positiva não implicada na inscrição do negativo do próprio sujeito, se o Outro não for também o 'seu' vazio, uma parcela relevante do que os 'dados' etnográficos dizem pode remanescer muda.

O que a psicanálise poderá, talvez, somar ao ofício etnográfico é trazer rigor analítico à consideração dos meios pelos quais o Outro necessariamente inscreve significantes com os quais se entretece o 'ser' observador.

Um bom exemplo dessa situação encontra-se no célebre mal-entendido entre artistas europeus e 'ciência' africana. Os primeiros 'viram' uma arte africana onde os segundos construíam registros realistas do que os impactava (KRAMER, 1993). O 'primitivo', esse objeto causa do desejo europeu, destaca-se da Europa enquanto tal e faz parte dos seus processos culturais.

Segundo Kramer (1993), o pensamento africano sempre suporta em conjunto espírito e experiência, sendo, por exemplo, a realidade dos espíritos vista como expressiva do impacto sensível do Outro no sujeito. Contra uma renitente ilusão de ótica etnocêntrica, os 'espíritos' africanos não necessariamente se substantivam metafisicamente. O que os caracteriza pode não ser nada de substancialmente invisível, mas um movimento que se percebe. "Por esta razão os Tonga comparam-no com o vento; eles chamam o espírito de 'vento' porque não vemos 
o vento. Conhecemos o que eles são pelo que eles fazem, assim como não vemos o vento, mas sabemos que ele está presente pelo que ele faz" (COLSON, 1969 apud KRAMER, 1993, p. 65).

Entre os mais conhecidos artefatos culturais africanos utilizados para dar suporte sensível ao Outro, mal-interpretados como 'arte' ou 'religião', destacam-se o recurso a máscaras e à possessão.

Segundo Kramer (1993), a máscara pode ser usada como amuleto, insígnia, não apenas na forma da mascarada, o que prova a sua natureza de timbre, significante. É geralmente o artifício de um rosto afigurador do Outro, artefato em cuja confecção se reúnem materiais e traços alusivos a significados socialmente compartilhados, que se compõem para dar uma forma plástica a esse 'Outro' culturalmente significativo. Dá 'corpo', em geral, ao 'seu' olhar, à 'sua' voz, e desempenha ritualmente tarefas simbolicamente reveladoras do seu papel e promotoras com eficácia do que se espera da sua intervenção.

Apesar do dispositivo das máscaras concorrer com a possessão, sendo incomum a sua convivência no mesmo contexto etnográfico (salvo uma segregação por gênero), não é impossível que, ao tocar uma máscara, se entre em transe (KRAMER, 1993). Aparentemente o mascarado 'tem' o outro e o possuído 'é' o outro, mas essas divisões nem sempre se mantêm tão nítidas. Embora a diferença entre o uso de máscaras e a possessão seja em princípio a do revestir-se de Outro com a de ser tomado pelo Outro, a diferença é sutil e não é seguro que o carregar uma máscara (metafísicas à parte) por si só não transfigure algo na identidade do portador.

Por outro lado, a ideia de que na possessão há uma metamorfose no outro parece ser uma ilusão etnográfica projetada como fantasia de uma religião africana que pode jamais ter existido. Pelo contrário, a possessão, em contextos africanos, parece servir para demarcar uma distância e uma diferença: "dançar para alguém é mostrar distância a esse alguém” (KRAMER, 1993, p. 132). Não se dança para ser igual ao que se dança, mas para tentar se apossar, mimeticamente, do estrangeiro e do estranho, marcando uma diferença. O que se almeja é dar expressão ao Outro, capturá-lo e controlá-lo. Na hipótese de cooptação ou assimilação, os ritos de possessão perdem força e a sua razão de 
ser. Não há possessão sem a preservação de uma relação de alteridade (KRAMER, 1993).

Na possessão não há verdadeira metamorfose. Mantém-se a alteridade. O uso de roupas e personagens europeus, por exemplo, comum em muitos ritos africanos, não significa adesão, identificação, mas demarcação. A atenção a esta perspectiva intra-africana ajuda a rever a ilusão de um africano supersticioso e dominado por outros demônios (metafísicos) que não o estrangeiro e o invasor de carne e osso.

Os traços de esculturas e de máscaras evocam rictos faciais de possuídos e vive-versa. Lavram-se como suportes da face do Outro, metonímias do 'seu' olhar, pura e simplesmente porque se oferecem aos nossos olhos. O realmente essencial em todos esses dispositivos parece ser afigurar estética e sensivelmente não como coisa, mas evocar Outro 'olhante' ou vociferante, mesmo que silenciosamente. Talvez daí derive, pelo menos em parte, o impacto 'estético' desses objetos. Eles 'dizem' alguma coisa em si mesmos, porque, ao serem comportados por pessoas empíricas, na verdade, essas carregam Outro que as atravessa e a toda a comunidade.

Ao ler atentamente o levantamento a que Kramer procedeu, é possível identificar constâncias quanto ao que é ou pode aparecer Outro em sociedades africanas:

1) OOutro 'inocente': sempre, antes do mais ena dependência da ontologia peculiar de cada cultura, o Outro é o inocente e a natureza selvagem (florestas, mundos aquáticos, etc.). O Outro pode ser o espaço da selva, do mar ou dos rios, o desumano, o mundo das coisas e do estrangeiro, o território além da civilização e das terras cultivadas. Mas sempre se trata de um cenário próximo, do qual se depende e a partir do qual se constroem laços com o mundo familiar. A fronteira psicológica efetiva, aqui, parecer ser a culpa, marca de desnaturalização. O tipificante do 'nós' passa por um 'pecado', do qual outros seres e outros homens poderiam estar isentos e, até por isso, serem (duvidosamente) encarados como 'superiores'. É bastante plausível que esse tipo de artifício, elaborado à exaustão em mitos de desobediência e castigo, no fundo não seja mais que um recurso para atribuir ao humano responsabilidade e, 
portanto, reivindicar o consolo de um pretenso poder sobre a determinação do seu fado e a inexorabilidade da sua finitude (BAIRRÃO, 2005).

2) O Outro tornado familiar: Parece haver a necessidade, culturalmente interpretada como obrigação, de uma parte do próprio 'ser' ser estrangeiro. A universal interdição do incesto e regras de parentesco que impõem a exogamia concretizam-na. Dessa forma, sempre há outro no próprio ser e 'perigos' daí advindos. Sempre há uma metade estrangeira do sujeito, embora seja oportuno fazer uma importante correção ao modo como o problema inicialmente foi recebido e tem sido apresentado em psicanálise: nem sempre o Outro gênero é a mulher. Em algumas sociedades podem ser os homens o 'objeto' de troca. O que realmente é estrutural é a exigência de uma parte do ser do sujeito provir 'de fora'. O que importa é que, venha do pai ou da mãe, uma parte de si é 'estranha' ao mais familiar. O Outro está constitutivamente inserido no âmago do mais originário de si mesmo, a cena primordial.

3) O familiar tornado Outro: o mais típico dessa articulação é o advento do radicalmente Outro na forma da morte - que provavelmente é o verdadeiro pano de fundo do complexo de Édipo (BAIRRÃO, 2010) -, no contexto africano elaborado principalmente na forma do culto ao ancestral.

Sem pretender que essa 'tipologia' esgote o assunto, ainda assim, pelas ressonâncias psicanalíticas que suscita, ela pode sugerir-se uma via de acesso a uma 'participação escutante' que possa reunir, sem preocupações com fronteiras disciplinares escolásticas, psicanálise e etnografia.

\section{Conclusão}

Mais do que se reportar a outrem e ao diferente, em psicanálise a noção de 'outro' refere-se a uma específica classe de objetos 'subjetivos' inobjetiváveis e a bastidores do si mesmo. 'Outro' ora se grafa 
com minúscula ora com maiúscula e ambos os usos não fazem sentido se não puderem de vez em quando de algum modo se reunirem num personagem, o qual nunca se reduz a um interlocutor, embora em alguma medida possa sê-lo. 'Outro' ora se propõe como 'rótulo' e lugar vazio a ser figurado por personagens previstos ou construídos pela rede de linguagem e inferíveis de um contexto enunciativo, ora parece se equivaler ao âmbito da significância. Ainda se aplica ao medular do sujeito e, vice-versa, 'eu' situa-se não apenas do Outro, mas também lá no Outro e como tal, ainda que tangível apenas na forma de remissão a 'um' significante.

Se à primeira vista parece difícil encontrar alguma congruência entre tão díspares contextos de aplicação da noção, o que se pode esperar de um intento de tomar o seu uso psicanalítico como horizonte cabível para iluminar o seu valor heurístico em outros ofícios contemporâneos, como o etnográfico? Será que o refinamento psicanalítico da categoria de alteridade pode aprofundar o alcance do seu emprego etnográfico, rever impasses e dissolver polêmicas, projetando a psicanálise na qualidade de método de investigação a um lugar de destaque no âmbito da epistemologia das ciências humanas?

Em princípio, sim. Evidências etnográficas permitem rever e consolidar o que Lacan propõe como topologia do sujeito, de maneira mutuamente enriquecedora. A psicanálise possibilita trazer à luz propriedades estruturais da alteridade tal como aparece em etnografias, invisíveis de um ponto de vista estritamente etnográfico.

Para examinar essa hipótese recorreu-se ao notável estudo de autoria de Fritz Kramer (1993) sobre a 'percepção' africana do Outro, feito com base em amplo levantamento de etnografias atinentes a populações sub-saharianas. Não se visou a esgotar o assunto, mas tão somente a sublinhar o seu valor heurístico.

Pode-se concluir que tanto em psicanálise como pelo menos em registros etnográficos africanos:

1) O Outro sempre é outro: o Outro é irredutível e a psicanálise proporciona um esclarecimento da sua razão de ser: a alternativa 
seria um colapso subjetivo, decorrente de uma absolutização do gozo.

2) O sujeito sempre em parte é outro: o sujeito não pode garantir-se em si mesmo. Para (não) ser, depende de uma alteridade intrínseca. O Outro é constituinte de si, seja a título de palavra, nada, sexo, morte ou pré-humanidade perdida.

3) O Outro é menos um: mesmo em contexto etnográfico, não há acesso factual nem ciência 'objetiva' do Outro que não dependa de um cálculo do presumido de si mesmo.

4) É importante repor o sujeito no seu efetivo estatuto de desconhecido para que a 'coleta de dados' permita subtrair das 'evidências' o próprio inconsciente. Uma boa 'etnografia' depende da particularidade dos traços do observador subtraídos à sua observação.

Dessa forma, dado o seu apreço e criterioso exame do papel da alteridade na estruturação do sujeito e por permitir aceder ao que se enuncia do Outro - certamente na acepção do que se ouve do Outro, mas também intrinsecamente na do que o sujeito se diz por intermédio do Outro -, a psicanálise mostra-se imprescindível para consolidar uma metodologia à altura das disciplinas científicas cujo 'objeto' não é uma coisa, mas sim alguém.

\section{Referências}

BAIRRÃO, J. F. M. H. O impossível sujeito: implicações do tratamento do inconsciente. São Paulo: Rosari, 2004.

BAIRRÃO, J. F. M. H. Função paterna e máscaras da morte: crítica antropológica e guinada lacaniana a propósito de um complexo polêmico. In: SIMANKE, R. et al. Filosofia da psicanálise: autores, diálogos e problemas. São Carlos: EDUFSCar; FAPESP, 2010. p. 407-422.

COLSON, E. Spirit possession among Tonga of Zambia. In: BEATTIE, J.; MIDDLETON, J. Spirit mediunship and society in Africa. London: Routledge, 1969. p. 69-102. 
KRAMER, F. The red fez. Tradução de Malcolm R. Green. London; New York: Verso, 1993.

LACAN, J. Propos directifs pour um congrès sur la sexualité féminine. In: LACAN, J. Écrits. Paris: Seuil, 1966. p. 725-736.

LACAN, J. Le Séminaire, livre III: les psychoses, 1955-1956. Paris: Seuil, 1981. LACAN, J. O Seminário, livro 16: de um Outro ao outro (1968-1969). Tradução de Vera Ribeiro. Rio de Janeiro: Jorge Zahar, 2008.

Recebido: 13/04/2011

Received: 04/13/2011

Aprovado: 18/05/2011

Approved: 05/18/2011 